\title{
Microbial Aspects in Wastewater Treatment - A Technical Review
}

\author{
Arezoo Dadrasnia ${ }^{1,2}$, Mohammed Maikudi Usman ${ }^{1,3}$, Kang Tzin Lim ${ }^{1}$, Rita Devi Velappan ${ }^{1,}$ Nasser \\ Shahsavari ${ }^{4}$, Pravin Vejan ${ }^{1}$, Ahmad Fahim Mahmud ${ }^{1}$ and Salmah Ismail ${ }^{*}$ \\ ${ }^{1}$ Department of Biohealth Science, Institute of Biological Sciences, Faculty of Science, University of Malaya, \\ 50603, Kuala Lumpur, Malaysia \\ ${ }^{2}$ Centre for Research in Waste Management, Institute of Research Management and Monitoring, University of \\ Malaya, 50603 Kuala Lumpur, Malaysia \\ ${ }^{3}$ Department of Biotechnology, School of Pure and Applied Sciences, Modibbo Adama University of Technology, \\ PMB 2076, Yola, Nigeria \\ ${ }^{4}$ Department of Agricultural Biotechnology, Hajiabad Branch, Islamic Azad University, Hajiabad, Hormozgan, \\ Iran \\ Email: salmah_r@um.edu.my
}

\begin{abstract}
Generation of wastewater is just unavoidable but its discharge into the environment is of great concern. Wastewater mainly comprised of any unwanted waste that could pollute our water system including sewage sludge, wastewater from domestic, industrial, dairy, fish canning and oil and gas industry. Since the early 1990s, microbial treatment processes have gained increasing attention due to its facility and high efficiency compared to conventional techniques. This paper focuses on the essential mechanisms involved in different microbial treatment techniques and special attention on the most recent challenges and developments will be highlighted in this review.
\end{abstract}

Keywords: Biological treatment, bioaugmentation, environmental pollution, wastewater.

\section{Introduction}

Access to clean water is considered a fundamental human right that is denied to large swathes of the world's population and on top of that, availability of clean water has utmost impact on human development. The urban population is set to have doubled to more than 5 billion by the year 2030 globally and so, if unchecked, such problems associated with water pollution will grow with the unavoidable knock-on effects on public health [1]. Thus, it is essential that as the economies of the worst affected countries grow, a proportion of their wealth would be spent on sanitation infrastructure. As a topic of major concern, the amount and quality of waste produced and discharged into natural water bodies have ruled headlines of various international media outlets, and the wealthiest countries invest a significant amount of effort for curbing the pollution of vast populations [1]. Worldwide reports of subsurface water contamination with heavy metal have become a serious public health-related issue and pertaining to that, adequate knowledge of the wastewater source is of utmost importance and it is crucial to identify its biological, chemical and physical aspects and to conduct a suitable treatment strategy [2].

Therefore, varieties of water treatment technologies methods have been devised and continuously improved over the time with the betterment of research facilities throughout the world. Based on the classifications of the concerned wastewater source, water treatment technologies also can be divided into biological, chemical and physical treatment techniques and further classified as in-situ or ex-situ technologies. To further shed light into the applications of in-situ and ex-situ technologies, in-situ remediation actions mean treatment conducted at the particular site, while ex-situ involves the elimination of pollutants at a remote place [3]. Flocculation is an excellent example for chemical water treatment action that is used for in-situ treatment of surface water and also groundwater. As for the example of physical water treatment, water diversion is one of it. However, these two modes of water 
treatments could prove to be less popular due to their negative sight effects. Flocculation could be a cautious mode of action as handling chemicals in bigger amount could be hazardous to the user and water diversion could cost a fortune done in large scale [4].

Last but perhaps the best treatment technique would be biological wastewater treatment technology. A term that could be a synonym to biological wastewater treatment technology would be 'biodegradation'. The breakdown of organic compounds by microorganisms such bacteria, fungi and micro-fauna giving rise to the formation of carbon dioxide and water or methane is biodegradation [5]. Microorganisms are arguably the key for degrading pollutant and maintaining the stabilization of the biological systems. There are several advantages of implementing biological wastewater treatment technologies in contrast to other treatment actions, relatively cheaper costs, minimal or no secondary excretion of pollutants and most importantly lower damaging effects on the environment [6]. In addition to that, biological wastewater treatment technology holds an economic advantage against both chemical and physical treatment technologies, in terms of maintenance costs and capital investments [7].

This review will therefore attempt to give a crystal-clear picture on the applications of biological wastewater treatment technologies specifically the intricate study of microbial aspects in wastewater treatment and its many advantages to mankind.

\section{Biological Treatment Technologies}

Aerobic treatment; in this method, the pond contains algae and bacteria that are able to survive under aerobic condition. Cao and $\mathrm{Li}$ [8] suggested electrolysis involving biological contact oxidation process for the treatment wastewater containing alkylbenzene sulfonate. Souza et al. [9] used biological activated carbon for the treatment of refinery wastewater in order to provide water intended for reuse. After 84 days, he observed an increase efficiency up to 65 per cent upon applying biological activated carbon. Activated carbon filters were saturated after 28 days. Moreover, the use of biocompunds (biosurfactant) has emerged as a promising method employed to enhance the fruitfulness of bioremediation processes. Biosurfactants are extracted biologically from the bacterial or yeast cell membrane components; they exhibit low level of toxicity and can be biodegraded because they can decrease the interfacial tension, surface tension, and the critical micelle concentration. Furthermore, these biocompunds can withstand a wide range of temperature and $\mathrm{pH}$ conditions and to some extent can affect interfaces. In addition, due to the present of naturally occurring macromolecules, such as glycolipids, fatty acids, and lipoproteins in biosurfactants, they are more suitable in petrochemical and environmental applications compared to synthetic and traditionally made chemical surfactants [10,11]. Previously, we have shown the potential of a native bacterium namely Bacillus salmalaya 139SI which enhanced the water solubility of crude oil waste and the sorption capacity with a high recovery of $\mathrm{Cr}(\mathrm{VI})$ from aqueous solution $[12,13]$. Bacterial strains belonging to genera Bacillus and Pseudomonas typically produce lipopeptidese biosurfactants.

Anaerobic treatment; this pond is considered as a fermentation process that is very efficient and costeffective for eliminating BOD and COD high concentrations especially in removing biodegradable organic compounds from solution. Anaerobic treatment system has been employed in industrial wastewater treatment for many years [14]. In the process of anaerobic digestion biogas containing methane and carbon dioxide will be produced. This process can accrue in those places that redox potential is low and organic material is available. Both anaerobic and aerobic systems can be used in treatment of wastewater. Table 1, shows a comparison in anaerobic and aerobic systems.

Table 1. Comparison of anaerobic and aerobic systems [14-17]

\begin{tabular}{l|l|l}
\hline Parameters & Anaerobic & \multicolumn{1}{c}{ Aerobic } \\
\hline Nutrient requirement & Low & High \\
\hline Effluent quality & Medium & High \\
\hline Temperature sensitivity & High & Low \\
\hline Energy requirement & Moderate & High \\
Efficiency in removal of organic & High & High \\
\hline Odor & High potential to produce & Low potential to produce \\
\hline
\end{tabular}




\section{$3 \quad$ Ecology of Biological Waste Water}

The micro-organisms have their own properties during waste water treatment and mainly focus on the process that is being applied. There are few types of treatment which consists of facultative ponds, anaerobic treatment, and aerobic process involving bacteria and protozoa but its role is inessential. Fungus has the survival rate in condition such as reduced $\mathrm{pH}$ and less nitrogen which as a result fungus is considered in waste water treatment. Thus, fungus has the capability to deteriorate the sludge settle ability due to its filamentous structure which might affect the process. The presence of rotifer at beginning of waste water treatment is a good sign as it can absorb dispersed bacteria and organic matter [18].

\subsection{Importance of Microalgae in Waste Water Treatment}

Microalgae have the photosynthetic capability which can convert solar energy to biomass and have established the efficiency to absorb some nutrient such as nitrogen and phosphorus in short span time. Some types of genera algae found in stabilization pond are Ankistrodesmus, Golenkinia, Euglena and Micractinium. These microalgae can be used to treat wide range of sewage system and it is counted as tertiary treatment process which removed organic ion. Removal organic ion achieved by chemically or biologically and biologically treatment seems to be more promising [19].

\subsection{Stabilization of Ponds}

Waste stabilisation ponds are a non-conventional system to treat wastewater. This wastewater stabilization known as biological treatment system which is accessible to operate and limited equipment maintenance promotes better sludge thickening [20]. The perfect architecture will help to cultivate bacteria and algae which will efficiently and completely dispose organic waste in water thus this will decrease problem during treatment and disposal of wastewater [21].

\subsection{Bacteria and Structural Units}

Heterotrophic bacteria play an important role in removing organic matters in waste water treatment system. These bacteria work during the waste water treatment in the clusters forms as floc, biofilm or granule.

\subsubsection{Extracellular Polymeric Substances (EPS)}

The clusters or group of microorganisms produce EPS. EPS is created upon cells lysis, cell secretion and absorption of substances from waste water environment. Colloid of EPS is made of proteins and polysaccharides and is important in determining the biomass structure and properties. One of the parameters in treatment can trigger the EPS production in order to sustain and protect the biomass structure against toxic [22]. EPS also constructs a diffusion barrier that scales down the toxicity of compounds around the cells [23].

\subsubsection{Flocs}

Floc is an activated sludge which forms bacteria colony by the attachment of the cells and pollutant from waste water by physiochemical reaction. Flocs consist of bacteria and EPS [24]. Flocs stability is mediated by the content of the microorganism and factor as environmental stress will cause floc to be fragmented [25].

\subsubsection{Biofilm}

Biofilm formational is formed when microorganism structure is immobilized on a solid platform which is supported through electrostatic interaction, hydrophobic interaction and covalent bonds. It is facilitated by microorganism itself, its component such as cilia, fimbriae, cell wall and EPS. Mass transport in the biofilm depends on diffusion meanwhile thickness of the biofilm depends on the ability of substances and oxygen penetration. Genetic transfers happen when channel and pores crossed into biofilm. These changes can cause resistance to the toxic compounds [26].

\subsubsection{Aerobic Granules}

Microbial self-immobilization is one of the examples of aerobic granules. The technology has a good 
setting ability of granules and high concentration of microorganism in its structure. The presence of slow growing bacteria and denitrification promotes aggregation and formation of granules [27].

\subsection{Protozoa}

Protozoa play roles in removing of the organic matter in sewage but as the main role as predatory activity they conduct on bacteria in liquid medium. Protozoa is also related in activation sludge in wastewater treatment besides bacteria. Protozoa also maintain good balance in the biological ecosystem by eliminating the excess bacteria, promote their growth and promote floc [28]. Protozoa can mineralize carbon in activated sludge and can eliminate mineral nutrient when the carbon source is expedited by bacteria. Meanwhile, protozoa can secrete growth stimulating substances that can promote bacterial activity [29].

\section{Biological Treatment with Activated Sludge}

Wastewater treatment is necessary for water pollution which has posed various threats to human health, ecology and economic stability globally. At present, biological treatment especially activated sludge is a remarkable approach because it is considered environmentally-friendly with lower cost to implement and high retention efficiencies towards target pollutants [30]. Wastewater characterization is an important factor in setting up a relevant effective management strategy or treatment process, for example, wastewater composed of Sulphur dioxides and nitrogen oxides, thus, sulphide-oxidizing bacteria (SOB) and nitrate-reducing bacteria (NRB) are mainly used [31]. In order for the bacteria to survive and grow they need carbon, energy source and oxygen for aerobic microorganisms. Activated sludge is comprised of the aggregation of suspended microbial for bio flocculation which usually held together by the extracellular polysaccharides (EPS) excrete by the bacteria themselves [32]. In general, activated sludge consists of the following tanks including, aeration tank for oxygen supply to mixed liquor, settling tank or final clarifier to allow the biological flocs to settle and storage tank to receive the final effluent (liquid waste) [31, 33].

Activated sludge is a biological treatment to remove the organic compounds through the metabolic reactions of microorganism, for instance, to oxidize carbonaceous or nitrogenous biological matter mainly ammonium and nitrogen and remove nutrients such as phosphorous and nitrogen by utilizing the process of adsorption then degradation [30]. According Liu et al. [30], the relationship between microorganism growth and the adsorption capacity is representing the removal process of organic matter in the wastewater. The removal efficiency of organic components in wastewater mainly depends on the adsorption process whereas the microorganism growth depends on the organic degradation rate since microorganisms could only utilize the organic matters adsorbed onto activated sludge as nutrients for growth instead of the originally presented organic matters in the wastewater [30].

In addition, to enhance the removal rate of sludge degradation, the elimination of EPS is crucial during pre-treatment since EPS is a constitutive element of sludge floc matrices [32]. Formation of EPSenzyme complexes could decrease the reaction of enzymes constituted on the sludge thus surfactant such as sodium dodecyl sulphate (SDS) can be used for removing the EPS in order to increase the acquirable of substrates to microorganism and to improve the lytic activity for anaerobic biodegradability thus increase the biogas yield production [32]. Besides, anionic surfactant such as linear alkylbenzene sulphonate (LAS) for example sodium salt of dodecylbenzene sulphonate is proven to affect the morphology of the activated sludge, causing fragmentation of the flocs and lysis of the protozoa cells [34]. LAS at the concentration of $3 \mathrm{mg} \cdot(\mathrm{g} \cdot \mathrm{dss})^{-1}$ can stimulate the removal of chemical oxygen demand, phosphorus release and the respirometric activity of the sludge, however, increasing the concentration of LAS up to $15 \mathrm{mg} \cdot(\mathrm{g} \cdot \mathrm{dss})^{-1}$ will have an opposite effect [34].

Furthermore, powdered activated carbon-activated sludge (PAC-AS) is an effective approach to activated sludge which proved to show heighten COD removal efficiencies in great lengthy operation and enhance the accumulation of biomass, sludge settle ability and the rate of specific oxygen uptake within the biological system [35]. PAC is able to facilitate the removal of hydrophobic substance as well as acidic metabolic products due to its strong adsorption complement for both hydrophobic and acidic substances accumulated during the microbial metabolism [35]. The rate of sulphide and nitrate removal 
from wastewater increased upon addition of wastewater activated sludge fermentation liquid as carbon source instead of glucose in culture medium of microbial system [36]. According to Zhang et al. [37], bacteria that suggested involving in wastewater activated sludge fermentation liquid are Sulfurospirillum sp., Thauera sp., Azoarcus sp., Arcobacter ap. and Clostridium sp.

\section{Microbial Composition in Wastewater Treatment Plant}

In waste water treatment plants, biodegradation of wider range of substrate is better compared to the one in pure culture considering the fact that microorganisms are organized in species-rich structure [38]. In biological wastewater treatment techniques, most of the microorganisms exist in microbial aggregates form including biofilms, flocs and granules. Application of various electron microscopic methods revealed the presence of a complex high-molecular-weight mixture of polymers called extracellular polymeric substances in pure cultures, activated sludge, biofilms, and granulated sludge [39]. EPS on the microbial surface plays an important role of keeping the microbial aggregates together in a three-dimensional gellike hydrated matrix via physicochemical interactions that are weak in nature. These weak forces of interactions include hydrogen bonding, electrostatic, hydrophobic and van der Waals force [40]. EPS are metabolic byproducts that accumulate on the surface of bacterial cell [41]. They are formed by microorganisms present in bioreactors upon consumption of organic materials present in wastewater. Different mechanisms such as secretion, excretion, lysis of cell as well as sorption of components of waste water contribute toward accumulation of EPS [40]. From engineering point of view, EPS possess some essential properties such as biosorption potential and biodegradability [42]. EPS consists of a variety of organic macromolecules including polysaccharides, proteins, nucleic acids, phospholipase and other nonpolymeric components of lower molecular weight [43]. Organic substances like humic substances as well as uronic acid were also reported present in EPS [44].

\subsection{Microbial Community in Wastewater Plants}

Revelation of the many and various microbial communities will undoubtedly provide understanding into wastewater treatment. In this regard, various biological methods/techniques including denaturing gradient gel electrophoresis, terminal-restriction fragment length polymorphism, 16S rRNA gene clone library and fluorescence in situ hybridization analyses are utilized leading to an extensively evaluation of microbial community in wastewater treatment plants [45]. The culturing approach toward microbial community characterization is considered direct and effective. However, most of the bacteria present in the natural environmental setup cannot be cultured in the laboratory using synthetic medium [46], hence application of molecular based techniques is of paramount important.

In municipal wastewater treatment plants, the phylum Proteobacteria has appeared predominant (21$62 \%)$ and the most abundant class of the phylum is Betaproteobacteria, largely involved in organic and nutrient removal. Acidobacteria, Bacteroidetes and Chloroflex are the subdominant phyla [37]. Recently, Meerbergen et al. [47] assessed the microbial composition of textile wastewater treatment plant in comparison to microbial communities from municipal wastewater treatment plant using pyrosequencing technique in an attempt to understand key microbes performing well in purification of textile wastewater. Their study indicated more abundant nitrifying and denitrifying bacteria as well those involved in phosphate accumulation whereas in textile wastewater plant, Sulphur reducing bacteria were almost found [47]. In an attempt to identify microbial coal-mine water treatment system, an illuminethroughput sequencing method was employed. The study, revealed the presence of Azoarcus, Comamonas, Nitrosomonas, Nitrospira, Ohtaekwangia, Pseudomonas, Thiobacillus and Thauera as the major genera. These communities were quite contrasting from those in municipal sludge. Understanding of microbial communities from coal wastewater treatment plant will assist toward development of effective approach for coal-mine wastewater treatment [45].

\subsection{Modeling the Biological Proceeding}

The activated sludge process is widely applicable in treatment of wastewater to decrease the levels of effluents in contaminated wastewater [48]. Activated sludge system has become the admired biological 
process employed in treatment of different kinds of wastewater globally; many advanced dynamic mathematical models were developed for evaluation and prediction of the process effectiveness of diverse wastewater treatment plants in the course of biological nutrient removal. A series of activated sludge models (ASM) were developed by International water association (IWA); including ASM1, ASM2, ASM2d, ASM3. These models were considered good solutions in prediction of efficiencies of biological process [49].

In ASM1 there is process that involves the microbial nitrification, the microbial denitrification and the microbial carbonization reactions, the enhanced version ASM2 is an improved version of ASM1 with an additional process of the biological and chemical phosphorus removal [50]. In another study, a metabolic model was applied: polyphosphate accumulating organisms (PAOs) and glycogen accumulating organisms (GAOs) were incorporated so as to describe transformations of full-scale improved biological phosphorus removal activated sludge from wastewater treatment plants biochemically [51].

\section{Microbial Electro-Remediation Technology}

Large volume of metal-laden wastewater is generated due to human activities and rapid industrialization. The metal(loid)s contaminated water posts great health and environmental threats, due to toxic potentialities and carcinogenic effects, strict guidelines have been embraced for discharge of various metal ions in wastewaters in order to avoid environmental contamination. For instance, based on the US EPA priority pollutants listed, naturally occurring arsenic (As) as a highly toxic metalloid, and catastrophic, over 250 million people are facing arsenic toxicity around the globe, especially from developing nations, which result in neurological damage and even death [52]. An ideal treatment approach is not getting rid of the metals but accumulating and recovering them during the treatment process. Although several methods for arsenic treatment or removal from water and wastewater are available, recently researches are geared toward development of technological way outs that sound economically realistic, with reduced costs and maximized efficiency as well as environmental friendly. Urgent research and development is therefore seriously needed in this specific direction to further advance the novel technology and broaden its scope of application to real situations toward pollution remediation. This is really required in order to find solution to the conventional techniques such as coagulation, precipitation and adsorption involved in metal removal, which is generally considered less effective [53]. Activated carbon based adsorption, ion exchange and membrane technologies approaches are decidedly expensive for the treatment involving large volume of industrial effluent and wastewater containing low amount of heavy metal ions, these techniques cannot be employed at large industrial scale [54].

Therefore, research on new, acceptable and cost-effective methods of metal removal from water has recently become an area of enormous research pursuit. In recent years, bio-electrochemical system (BES) and in particular microbial fuel cells (MFCs) emerged as a new remediation method primarily utilized to mobilize pollutants for recovery or reduction in the subsurface. This technology appears encouraging wastewater treatment and metal recovery through bio-electro catalysis considering the fact that algae, bacteria, fungi and yeast can reduce and deposit the metal ions. BES has raised considerable attention for bioremediation applications [55]. Interestingly, heavy metal-bearing wastewater can be treated in both anode and cathode chambers of MFCs [56]. The general idea behind the process is that the biological conversions event at the positively charged electrode (anode) are used to convey electrons to the negatively charged electrode (cathode) and drive reduction with precipitation of metal(loid)s by using them as terminal electron acceptor. Therefore, BES provide a novel platform for integrated treatment of wastewater via oxidation and reduction reactions for recovering energy, water and metal(loid)s. Recovery of metal species through the course of conventional MFC function, takes MFCs one-step further of other waste treatment technologies. When contaminants are serving as electron acceptors in the MFC cathode chamber, the environmental advantages of MFCs could be further improved. Recovering of metals in the course of electricity generation certainly eliminates the energy need for treatment process [56]. 


\section{Conclusion}

Treatments adopted are geared toward acheiving common goal of water quality standards to ensure environmental protection. Wastewater are being generated from different sources ranging from industrial productions to domesticactivities, and various treatment techniques are put in place, which includes biological methods. For effectual treatment, considerations are paid to charcterisation of wastewater, requirement of treated wastewater standard, alternative ways of treatment as well as associated sampling methods with analysis. In order to have better understanding and control measures of wastewater treatment processes, it is requisite and paramount to understand the role played by microbial community structure of the organisms taking part in the treatment processes. Generally, microorganism enzymes taking part in degradation of environment contaminants are very specific in catalysis for each substrate. However, when microorganisms are subjected to new growth conditions or substrates, they are capable of synthesizing new enzymes to produce energy and nutrients from different substrates or under new growth conditions after an acclimation period. Controlling the microorganism activities is essential, so as to utilize its potentials for bioremediation purpose. Several methods exist for the control of this activity like the designed pathways for precluding any biodegradation limitation, and the utilization of available genomic resources to construct the new pathways, and the explosion of entire-genome sequence information. Adoption of biological approach ahead of others is being canvassed because of its greener nature as well as its relatively lower cost. Yet, the time taken when utilizing biological approach of wastewater treatment is a recurring factor that is a disadvantage, and the wide range of pathogens in wastewater often rise concerns on the utilization of microbes in treatments.

Acknowledgments. The authors would like to acknowledge the support of the University of Malaya Research Program (UMRP) with grant number of RP023A-14AFR.

\section{References}

1. S. T. Oh, J. R. Kim, G. C. Premier, T. H. Lee, C. Kim, and W. T. Sloan, "Sustainable wastewater treatment: how might microbial fuel cells contribute," Biotechnology Advances, vol. 28, pp. 871-881, 2010.

2. I. Ferrera and O. Sánchez, 'Insights into microbial diversity in wastewater treatment systems: How far have we come?" Biotechnology advances, vol. 34, pp. 790-802, 2016.

3. K. K. Ng, X. Shi, S. L. Ong, and H. Y. Ng, "Pyrosequencing reveals microbial community profile in anaerobic bio-entrapped membrane reactor for pharmaceutical wastewater treatment," Bioresource technology, vol. 200, pp. 1076-1079, 2016.

4. C. D. Rocca, V. Belgiorno, and S. Meriç, "Overview of in-situ applicable nitrate removal processes," Desalination, vol. 204, pp. 46-62, 2007.

5. M. Nasr, A. Elreedy, A. Abdel-Kader, W. Elbarki, and M. Moustafa, 'Environmental consideration of dairy wastewater treatment using hybrid sequencing batch reactor," Sustainable Environment Research, vol. 24, no. 6, 2014.

6. S. Mingjun, W. Yanqiu, and S. Xue, "Study on bioremediation of eutrophic lake," Journal of Environmental Sciences, vol. 21, pp. S16-S18, 2009.

7. A. Mittal, "Biological wastewater treatment," Water Today, vol.1, pp. 32-44, 2011.

8. X. Cao and Y. Li, "Treatment of linear alkylbenzene sulfonate (LAS) wastewater by internal electrolysis-biological contact oxidation process," Water Science and Technology, vol. 147, no. 1, pp. 147-54, 2011.

9. B. M. Souza, A. C. Cerqueira, G. L. Sant Anna Jr, and M. Dezotti, "Oil-Refinery Wastewater Treatment Aiming Reuse by Advanced Oxidation Processes (AOPs) Combined with Biological Activated Carbon (BAC)," Ozone: Science \& Engineering, vol. 33, no. 5, pp. 403-409, 2011.

10.R. D. Rufino, J. M. Luna, G. M. C. Takaki, and L. A. Sarubbo, "Characterization and properties of the biosurfactant produced by Candida lipolytica UCP 0988," Electronic Journal of Biotechnology, vol. 17, no. 1, pp. 34-38, 2014.

11.S. N. Al-Bahrya, Y. M. Al-Wahaibib, A. E. Elshafiea, A. S. Al-Bemanib, S. J. Joshia, H. S. Al-Makhmaria, and H. S. Al-Sulaimani, "Biosurfactant production by Bacillus subtilis B20 using date molasses and its possible 
application in enhanced oil recovery," International Biodeterioration \& Biodegradation, vol. 81, pp. 141-146, 2013. 12.A. Dadrasnia, K. S. Chuan Wei, N. Shahsavari, M. S. Azirun, and S. Ismail, "Biosorption Potential of Bacillus salmalaya Strain 139SI for Removal of Cr(VI) from Aqueous Solution," International Journal of Environmental Research and Public Health, vol. 12, no. 12, pp. 15321-15338. 2015.

13.S. Ismail and A. Dadrasnia, "Biotechnological potential of Bacillus salmalaya 139SI: a novel strain for remediating water polluted with crude oil waste," PLoS ONE, vol. 10, no. 4, pp. e0120931, 2015.

14.Y. J. Chan, M. F. Chong, C. L. Low, and D. G. Hassell, "A review on anaerobic-aerobic treatment of industrial and municipal wastewater," Chemical Engineering Journal, vol. 155, no. 1-2, pp. 1-18, 2009.

15.R. A. Hamza, O. T. Iorhemen, and J.H. Tay, "Advances in biological systems for the treatment of high-strength wastewater," Journal of Water Process Engineering, vol. 10, pp. 128-142, 2016.

16.D. S. Srinivasa Raghavan, 12 - Anaerobic Treatment of Low-Strength Wastewater A2 - Lee, Duu-Jong, in Current Developments in Biotechnology and Bioengineering, V. Jegatheesan, et al., Editors. 2017, Elsevier. p. 293-320.

17.F. Y. Cakir and M. K. Stenstrom, "Greenhouse gas production: A comparison between aerobic and anaerobic wastewater treatment technology," Water Research, vol. 39, no. 17, pp. 4197-4203, 2005.

18.F. Pagnanelli, M. Sara, V. Francesco, and T. Luigi, "Heavy metal removal by olive pomace: biosorbent characterisation and equilibrium modelling," Chemical Engineering Science, vol. 58, no. 20, pp. 4709-4717, 2003.

19.N. Abdel-Raouf, A. A. Al-Homaidan, and I. B. M. Ibraheem, "Microalgae and wastewater treatment," Saudi Journal of Biological Sciences, vol. 9, no. 3, pp. 257-275, 2012.

20.H. G. Amir, Z. H. Shamsuddin, M. S. Halimi, M. F. Ramlan, and M. Marziah, "Effects of Azospirillum inoculation on N2 fixation and growth of oil palm plantlets at nursery stage," J. Oil Palm Res, vol. 13, pp. 42-49, 2001.

21.K. Vaajasaari and A. Joutti, "Field-Scale Assessment of Phytotreatment of Soil Contaminated with Weathered Hydrocarbons and Heavy Metals (9 pp)," Journal of Soils and Sediments, vol. 6, no. 3, pp. 128-136, 2006.

22.A. Cydzik-Kwiatkowska and Z. Magdalena, "Cycle length and COD/N ratio determine properties of aerobic granules treating high-nitrogen wastewater," Bioprocess and Biosystems Engineering, vol. 37, no. 7, pp. 13051313, 2014.

23.S. Andersson, S. G. Dalhammar, and G. Kuttuva Rajarao, "Influence of microbial interactions and EPS/polysaccharide composition on nutrient removal activity in biofilms formed by strains found in wastewater treatment systems," Microbiological Research, vol. 166, no. 6, pp. 449-457, 2011.

24.A. Raszka, M. Chorvatova, and J. Wanner, "The role and significance of extracellular polymers in activated sludge. Part I: Literature review," Acta hydrochimica et hydrobiologica, vol. 34, no. 5, pp. 411-424, 2006.

25.I. D. S. Henriques and N.G. Love, "The role of extracellular polymeric substances in the toxicity response of activated sludge bacteria to chemical toxins," Water Research, vol. 41, no. 18, pp. 4177-4185, 2007.

26.M. Mia, S. Zulkifli, and M. Maziah, "Use of Plant Growth Promoting Bacteria in Banana: A New Insight for Sustainable Banana Production," International Journal of Agriculture and Biology, vol. 12, no. 3, pp. 459-467, 2010.

27.J. Wan and M. Sperandio, "Possible role of denitrification on aerobic granular sludge formation in sequencing batch reactor," Chemosphere, vol. 75, no. 2, pp. 220-227, 2009.

28.M. D. Motta, M. N. Pons, H. Vivier, A. L. Amaral, E. C. Ferreira, N. Roche, and M. Mota, "The study of protozoa population in wastewater treatment plants by image analysis," Brazilian Journal of Chemical Engineering, vol. 18, pp. 103-111, 2001.

29.P. Madoni, "Protozoa in wastewater treatment processes: A mini review," Italian Journal of Zoology, vol. 78, no. 1, pp. 3-11, 2011.

30.X. Liu, L. Li, R. Bian, D. Chen, J. Qu, G. W. Kibue, G. Pan, X. Zhang, J. Zheng, and J. Zheng, "Effect of biochar amendment on soil-silicon availability and rice uptake," Journal of Plant Nutrition and Soil Science, vol. 177, no. 1, pp. 91-96, 2014.

31.R. O. Cristóvão, C. Gonçalves, C. M. Botelho, R. J. E. Martins, J. M. Loureiro, and R. A. R. Boaventura, "Fish canning wastewater treatment by activated sludge: Application of factorial design optimization: Biological treatment by activated sludge of fish canning wastewater," Water Resources and Industry, vol. 10, pp. 29-38, 2015 . 
32.S. Kavitha, C. Jayashree, S. A. Kumar, I. T. Yeom, and J. R. Banu, "The enhancement of anaerobic biodegradability of waste activated sludge by surfactant mediated biological pretreatment," Bioresource technology, vol, 168, pp. 159-166, 2014.

33.T. Hasegawa and S. Hasegawa, "Activated sludge process," 1977, U.S. Patent No. 4,055,490.

34.A. Dereszewska, S. Cytawa, R. Tomczak-Wandzel, and K. Medrzycka, "The effect of anionic surfactant concentration on activated sludge condition and phosphate release in biological treatment plant," Pol J Environ Stud. (in press) DOI, 2015. 10.

35.Q.-Y. Hu, M. Li, C. Wang, and M. Ji, "Influence of powdered activated carbon addition on water quality, sludge properties, and microbial characteristics in the biological treatment of commingled industrial wastewater," Journal of Hazardous Materials, vol. 295, pp. 1-8, 2015.

36.X. Wang, Y. Zhang, T. Zhang, J. Zhou, and M. Chen, "Waste activated sludge fermentation liquid as carbon source for biological treatment of sulfide and nitrate in microaerobic conditions," Chemical Engineering Journal, 2016, vol. 283, pp. 167-174. 47.

37.X. Zhang, X. Li, Q. Zhang, Q. Peng, W. Zhang, and F Gao, "New insight into the biological treatment by activated sludge: the role of adsorption process," Bioresource technology, vol. 153, pp. 160-164, 2014.

38.A. Cydzik-Kwiatkowska and M. Zielińska, "Bacterial communities in full-scale wastewater treatment systems," World Journal of Microbiology and Biotechnology, vol. 32, no. 4, pp 1-8, 2016.

39.G. P Sheng, H.-Q. Yu, and X.-Y. Li, "Extracellular polymeric substances (EPS) of microbial aggregates in biological wastewater treatment systems: A review," Biotechnology Advances, vol. 28, no. 6, pp. 882-8946, 2010.

40.B. J. Ni, F. Fang, W-M. Xie, M. Sun, G-P. Sheng, W-H. Li, and H-Q. Yu, "Characterization of extracellular polymeric substances produced by mixed microorganisms in activated sludge with gel-permeating chromatography, excitation-emission matrix fluorescence spectroscopy measurement and kinetic modeling," Water Research, vol. 43, no.5, pp. 1350-1358, 2009.

41.H. Liu and H. H. P. Fang, "Extraction of extracellular polymeric substances (EPS) of sludges," Journal of Biotechnology, vol. 95, no. 3, pp. 249-256, 2002.

42.A. G. Geyik, B. Kılıç, and F. Çeçen, "Extracellular polymeric substances (EPS) and surface properties of activated sludges: effect of organic carbon sources," Environmental Science and Pollution Research, vol. 23, no. 2, pp. 1653-1663, 2016.

43.A. Pal and A. Paul, "Microbial extracellular polymeric substances: central elements in heavy metal bioremediation," Indian Journal of Microbiology, vol. 48, no. 1, pp. 49-64, 2008.

44.S. S. Adav and D.-J. Lee, "Extraction of extracellular polymeric substances from aerobic granule with compact interior structure," Journal of Hazardous Materials, vol. 154, no. 1-3, pp. 1120-1126, 2008.

45.Q. Ma, Y-Y. Qu, X-W. Zhang, W-L. Shen, Z-Y. Liu, J-W. Wang, Z-J. Zhang, and J-T. Zhou, "Identification of the microbial community composition and structure of coal-mine wastewater treatment plants," Microbiological Research, vol.175, pp. 1-5, 2015.

46.L. Ye and T. Zhang, "Bacterial communities in different sections of a municipal wastewater treatment plant revealed by 16S rDNA 454 pyrosequencing," Applied microbiology and biotechnology, vol. 97, no. 6, pp. 26812690, 2013.

47.K. Meerbergen, M. V. Geel, M. Waud, K. A. Willems, R. Dewil, J. V. Impe, L. Appels, and B. Lievens, "Assessing the composition of microbial communities in textile wastewater treatment plants in comparison with municipal wastewater treatment plants," MicrobiologyOpen, John Wiley, 2016.

48.M. I. Nelson and H. S. Sidhu, "Analysis of the activated sludge model (number 1)," Applied Mathematics Letters, vol. 22, no. 5, pp. 629-635, 2009.

49.X. Wua, Y. Yanga, G. Wub, J. Maoa, and T. Zhou, "Simulation and optimization of a coking wastewater biological treatment process by activated sludge models (ASM)," Journal of Environmental Management, vol. 165, pp. 235-242, 2016.

50.Z. Jia, M. Limin, and S. Houran, "Research advance of the model of activated sludge process to wastewater treatment," in Information Technology and Mechatronics Engineering Conference (ITOEC ) on 2015, pp. 240-24.

51.A. B. Lanham, A. Oehmen, A. M. Saunders, G. Carvalho, P. H. Nielsen, and M. A. M. Reis, "Metabolic modelling of full-scale enhanced biological phosphorus removal sludge," Water Research, vol. 66, pp. 283-295, 2014. 
52.US Environmental Protection Agency, Priority pollutants, Appendix A to 40 CFR Part 423, Available: http://water.epa.gov/scitech/methods/cwa/pollutants.cfm.

53.X. Guan, H. Dong, J. Ma, and L. Jiang, "Removal of arsenic from water: Effects of competing anions on As(III) removal in KMnO4-Fe(II) process," Water Research, vol. 43, no. 15, pp. 3891-3899, 2009.

54.R. K. Gautam, A. Mudhoo, G. Lofrano, and M. C. Chattopadhyaya, "Biomass-derived biosorbents for metal ions sequestration: Adsorbent modification and activation methods and adsorbent regeneration," Journal of Environmental Chemical Engineering, vol. 2, no. 1, pp. 239-259, 2014.

55.U. Schroder, F. Harnisch, and L.T. Angenent, "Microbial electrochemistry and technology: terminology and classification," Energy and Environmental Science, vol. 8, no. 2, pp. 513-519, 2015.

56.A.S. Mathuriya and J.V. Yakhmi, "Microbial fuel cells to recover heavy metals," Environmental Chemistry Letters, vol. 12, no. 4, pp. 483-494, 2014. 